\title{
Instrumentational operation and analytical methodology for the reconciliation of aerosol water uptake under sub- and supersaturated conditions
}

\author{
N. Good $^{1, *}$, H. Coe ${ }^{1}$, and G. McFiggans ${ }^{1}$ \\ ${ }^{1}$ Centre of Atmospheric Science, School of Earth Atmospheric and Environmental Sciences, University of Manchester, \\ Manchester, UK \\ *now at: Laboratoire de Météorologie Physique, Blaise Pascal Univ., Clermont Ferrand, France
}

Received: 30 September 2009 - Published in Atmos. Meas. Tech. Discuss.: 1 February 2010

Revised: 27 August 2010 - Accepted: 13 September 2010 - Published: 15 September 2010

\begin{abstract}
The methodology for the operation and calibration of a hygroscopicity tandem differential mobility analyser (HTDMA) and cloud condensation nuclei counter ( $\mathrm{CCNc})$ for size-resolved measurements of aerosol water uptake are presented. A state of the science aerosol thermodynamic model is used to benchmark the performance of the instruments. The performance, calibration and operation of the instruments is then demonstrated in the field.
\end{abstract}

\section{Introduction}

The size and composition of aerosol particles determines their ability to take up water. The conditions they experience in the atmosphere determine their behaviour. Atmospheric conditions and atmospheric aerosol can vary greatly spatially and temporally. Therefore understanding aerosol wateruptake in a range of conditions (including sub-saturated relative humidities and the supersaturated conditions found in clouds) is necessary in order to accurately describe their role in atmospheric physics and chemistry. In turn theoretical descriptions of aerosol water uptake can be informed by and must be evaluated against observed behaviour.

In order for aerosol hygroscopic growth and $\mathrm{CCN}$ activity to be characterised, and theoretical or empirical descriptions of this behaviour to be evaluated, these properties must be accurately measured. The hygroscopicity tandem differ-

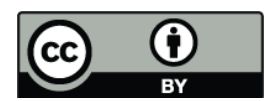

Correspondence to: G. McFiggans (g.mcfiggans@manchester.ac.uk) ential mobility analyser (HTDMA) (Liu et al., 1978; Swietlicki et al., 2008) can be used to accurately determine subsaturated hygroscopic water uptake of ambient aerosol particle populations. These instruments require careful operation and calibration as no standard for their design has been developed and applied consistently (Duplissy et al., 2009).

Various instruments have been developed to measure the ability of aerosol particles to act as CCN (Nenes et al., 2001). One such instrument is the Droplet Measurement Technologies (DMT) CCN counter (CCNc) (Roberts and Nenes, 2005). The DMT CCNc's operation has been characterised in several studies (Rose et al., 2008; Lance et al., 2006). The DMT CCNc's performance relies on the temperature $(T)$ gradient set down a conductive column to generate a constant centreline supersaturation to which the aerosol sample is exposed. Lance et al. (2006) showed that modelling the CCNc's supersaturation profile assuming the $T$ measured on the outside of the column is equal to the $T$ directly on the inside of the wall is not adequate to determine the centreline supersaturation $(S)$ precisely. The difference in temperature results from the thermal resistance of the columns' walls. Lance et al. (2006) note that the thermal properties of the walls may vary from instrument to instrument and with time. Rose et al. (2008) demonstrate the operation of a DMT CCNc under a range of conditions. Rose et al. (2008) show that calculating the thermal efficiency (Lance et al., 2006) and correcting the supersaturation derived from a model of the instrument, cannot always reconcile their measurements to theoretical values from thermodynamic models. It is predicted theoretically and shown in practice that the operating conditions (absolute $T$, pressure and and flow rate) will change the

Published by Copernicus Publications on behalf of the European Geosciences Union. 
centreline supersaturation set by a DMT CCNc for a given temperature gradient $(\delta T)$ down the column (Roberts and Nenes, 2005; Lance et al., 2006; Rose et al., 2008), however the theoretical and inferred (from test aerosol calibrations) centreline supersaturation may not match.

In this paper a procedure to characterise and validate the operation of a HTDMA and CCNc to measure atmospheric aerosol hygroscopic properties is outlined with the aim of achieving reliable and well characterised measurements of aerosol water uptake and potential CCN activity. The methodology for determination of operational supersaturation is not reliant on accurate knowledge of the actual centreline temperature profile. The centreline supersaturation is inferred from the observed CCN activity of aerosol of known composition with respect to a reference thermodynamic model. It is not derived from the temperatures measured around the column. Only the repeatability of the temperature set-points between calibrations is assumed. Such a procedure may be used to evaluate long-term instrument drift in actual temperature in response to set-point values and to compare with supersaturation control by nominal temperature control.

\section{Instruments}

\subsection{HTDMA - principle of operation}

A HTDMA operates by selecting a dry $(<15 \% \mathrm{RH})$ quasimonodisperse aerosol sample of diameter $\left(D_{0}\right)$ using a differential mobility analyser (DMA1). The aerosol sample is then conditioned to a set relative humidity $(\mathrm{RH})$ in a humidifier. The RH conditioned aerosol is then sized using a second DMA (DMA2) conditioned to the same RH as the sample in order to determine the equilibrium diameter $(D)$ of the humidified aerosol. Data from a HTDMA is usually reported in terms of the hygroscopic growth factor $\left(\mathrm{GF}_{\mathrm{D} 0, \mathrm{RH}}\right)$ which is defined as:

$\mathrm{GF}_{D_{0}, \mathrm{RH}}=\frac{D(\mathrm{RH})}{D_{0}}$

The HTDMA operated here is described in detail by Cubison et al. (2005) and Duplissy et al. (2009). In summary the HTDMA uses a gore-tex humidifier to condition the aerosol sample. The sample is held for a residence time of $\approx 30 \mathrm{sec}-$ onds prior to being sized by DMA2. DMA2 is operated by discretely stepping across a range of sizes i.e. as a differential mobility particle sizer (Keady et al., 1983). DMA2 is stepped across a range of sizes to measure $\mathrm{GF}_{\mathrm{D} 0, \mathrm{RH}}$ in the range of 0.8 to 3 when operated at $90 \% \mathrm{RH}$, in order to cover the range of GFs in the ambient environment. In this mode of operation the HTDMA takes $\approx 10 \mathrm{~min}$ to step across the range of particle growth factors. DMAs 1 and 2 are both operated with volumetric sheath flows of $5.5 \mathrm{~L} \mathrm{~min}^{-1}$ and sample flows of $0.55 \mathrm{Lmin}^{-1}$.

\section{2 $\mathrm{CCNc}$ - principle of operation}

The CCNc operated here is built by Droplet Measurement Technologies (DMT CCN model version 1) and its design is based on the CCNc instrument described by Roberts and Nenes (2005). Rose et al. (2008) describe the DMT CCN version 2 , which is fundamentally the same instrument with some minor differences. The CCNc exposes the aerosol sample to a supersaturation as it is drawn along the centreline of a column, separated from the walls by a near saturated sheath air flow. The sample aerosol is conditioned to a constant temperature $\left(T_{\text {Inlet }}\right)$ with respect to which all the other temperatures in the $\mathrm{CCNc}$ are set. The temperature of the column is controlled at the top (to a temperature $\left(T_{1}\right)$, middle $\left(T_{2}\right)$ and bottom $\left(T_{3}\right)$, where $\left.T_{3}>T_{2}>T_{1}\right)$ in order to achieve a smooth temperature gradient down the walls of the column. The walls of the column are continuously wetted. Heat and water vapour diffuses from the walls of the column towards the columns centreline, whilst the sheath flow draws the diffusing gases down the length of the column. Water vapour diffuses quicker than air. Therefore a supersaturation develops as water molecules which are near saturation concentration at point on the wall from which they originate, experience lower temperatures as they diffuse towards the centreline. The temperature is lower because the air diffusing to the same point on the centreline originates from a point further up the column which is cooler (because of the $T$ gradient applied to the column). The temperature gradient must be small compared to the aerosol inlet temperature to maintain a near constant centreline supersaturation.

Once particles reach the bottom of the column they enter an optical particle counter (OPC) located directly below the column. The OPC signal is used to count the number of particles in 20 bins between 0.5 and 20 microns in diameter. The OPC data is recorded at $1 \mathrm{~Hz}$.

The CCNc is operated in 2 modes in order to determine the size-resolved CCN activity of the sampled aerosol particles. In the first mode, a DMA is used to supply a single dry size cut of aerosol, the $\mathrm{CCNc}$ then sets a series of different supersaturations. The number of particles which activate at each supersaturation is then used to investigate the CCN activity of the aerosol. In the second mode of operation the supersaturation is held constant whilst the DMA is operated as a DMPS; stepping over a series of mobilities. The number of particles which activate into $\mathrm{CCN}$ as a function of size can then be used to investigate the CCN activity.

\section{Experimental configuration}

\subsection{Sample charge equilibrium}

Prior to entering the DMA, the sample aerosol is charge equilibrated using a Strontium-90 radioactive source. Aerosols can exist in various charged states (e.g. Maricq, 2006; Vana 
et al., 2006). Sub- $\mu$ m aerosol particles may be neutral or in positively or negatively charged states. The equilibrium charging probability can be calculated (Fuchs, 1963; Wiedensohler, 1988), allowing the number of charges on particles of a given mobility that are selected by a DMA to be determined if the raw (total number of particles detected by the CPC at each mobility) number size distribution of the aerosol is known. The DMAs used to size select the aerosol in this study, select negatively charged particles.

When operating a HTDMA it is usually assumed that all these particles sampled are singly charged. If the sample contains significant numbers of particles with multiple charges this may lead to erroneous interpretation of the data. The hygroscopic growth of simultaneously sampled different sized particles cannot be differentiated analytically (Gysel et al., 2009). The larger multiply charged particles may also have different growth factors due to the Kelvin effect and their chemical composition, further increasing the measurement uncertainty. It is therefore recommended that the fraction at each charge of the selected mobility is calculated in order to validate the HTDMA measurement (Duplissy et al., 2009). In the measurements presented here, multiply charged particles usually make up less than $\approx 20 \%$ of the number of particles sampled at each size and as such the HTDMA data is inverted assuming all particles carry a single charge.

When operating a CCNc in tandem with a DMA, particles with more than one charge may also be selected and sampled by the CCNc. The $\mathrm{CCN}$ activity of aerosols is sensitive to their size (McFiggans et al., 2006) therefore the size of the particles selected must be well defined. The DMA-CCNc measurement technique is often used in ambient and laboratory studies (e.g. Allan et al., 2008; Gunthe et al., 2009; Juranyi et al., 2009) and therefore the sampling of multiply charged particles must be minimised or accounted for. Several methods for correcting for multiply charged particles in DMA-CCNc measurements have been developed (Rose et al., 2008; Petters et al., 2007). The method used to correct for multiply charged particles in the DMA-CCN measurements presented here is outlined in Sect. 5.2.

The top panel of Fig. 1 shows the fraction of particles of a given charge that would be selected by a DMA as a function of mobility across 3 example size distributions (from a marine environment, smog chamber experiment and a nebuliser). The bottom panel shows the raw (averaged number concentration detected by the DMPS at each set mobility with no corrections applied) size distributions and the corrected (including multi-charge correction) number size distributions (Williams et al., 2007). The number distributions are plotted versus mobility diameter $\left(D_{p}\right)$, which is defined as:

$D_{p}(n=1)=\frac{n e C}{3 \pi \mu Z_{p}}$

where $n$ is the number of charges on the particle, $e$ is the electron charge, $C$ is the Cunningham slip correction factor,

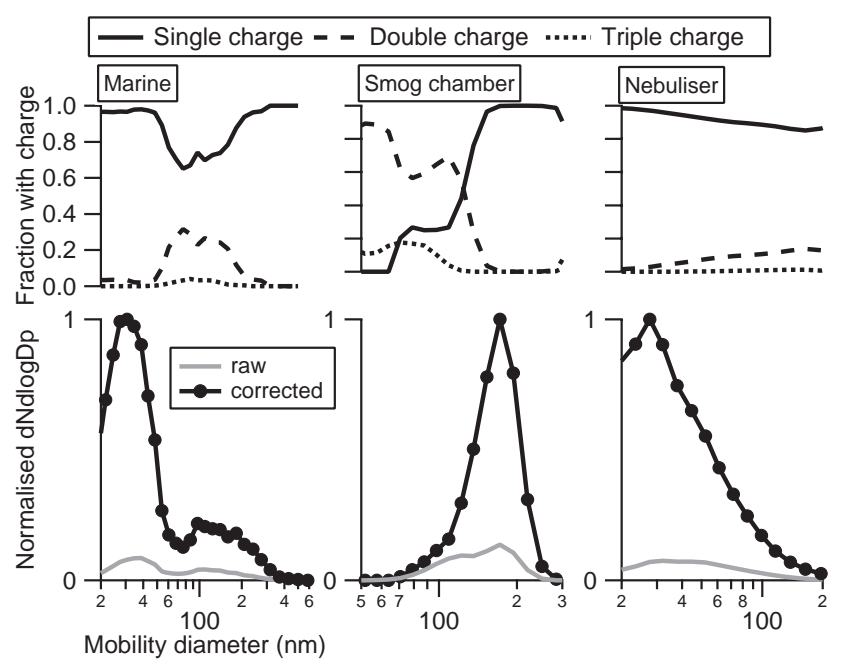

Fig. 1. Example size distributions and the fraction of particles with single, double and triple negative charges at each mobility diameter.

$\mu$ is the viscosity of air inside the DMA and $Z_{p}$ is the electrical mobility (Knutson and Whitby, 1975). For the marine distribution there is an increase in multiply charged particles between $\approx 80 \mathrm{~nm}$ and $\approx 200 \mathrm{~nm}$. The largest contribution of multiply charged particles occurs for $D_{p} s$ between the modes of the distribution because of the higher number of larger particles. For the smog chamber distribution there are more multiply charged particles at sizes below the mode than singlets, above the mode the singly charged fraction is close to 1. The number size distribution generated by the the nebuliser is composed mostly of singly charged particles (>90\%). The fraction of multiply charged particles increases with size up to $\approx 10 \%$ at $D_{p}=200 \mathrm{~nm}$.

For the nebuliser distribution the influence of multiply charged particles is generally small and will not impact measurements significantly. For the smog chamber distribution, the effect of multiple charging can be large as noted by other authors (King et al., 2009; Duplissy et al., 2009). For the marine distribution we see that there are some diameters which have quite large contributions, e.g. around $100 \mathrm{~nm}$, whilst others do not. It is therefore necessary to have a procedure to correct this data for multiply charging.

\subsection{HTDMA configuration}

Duplissy et al. (2009) review the instrumental parameters important to maintaining reliable HTDMA operation and data collection. The flows and temperatures in the DMAs are monitored continuously as described by (Cubison et al., 2005) to ensure they operate reliably and stably. An important feature of the HTDMA set-up to note is that the temperature is measured inside the bottom of DMA2 and in the sheath excess at the top of DMA2, to ensure the RH is constant and well defined in the DMA. The residence time of 


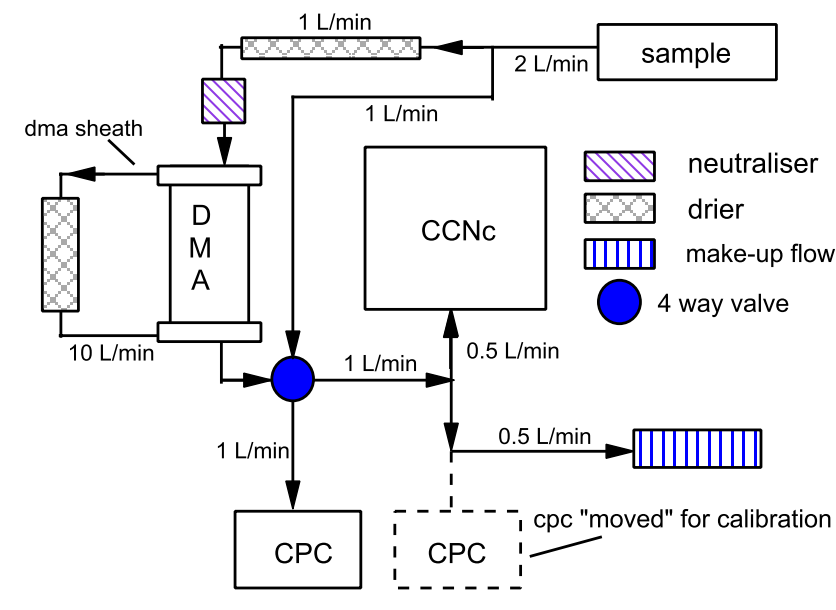

Fig. 2. CCN-DMA experimental set-up. Schematic showing how the DMA and CCNc are coupled. The 4 way-valve can be set in 2 positions, such that the $\mathrm{CCN}$ is either sampling aerosol from the DMA or directly from the sample and the DMA is either supplying the CCNc or the CPC. For the calibrations the CPC is connected so it samples simultaneously to the CCNc and the make-up flow is reversed to main $1 \mathrm{~L} \mathrm{~min}^{-1}$ sample flow.

the humidified aerosol sample prior to sizing in DMA2 is $\approx 30 \mathrm{~s}$, so that the sample has time to equilibrate (Sjogren et al., 2007). The accuracy the HTDMA's measurements are ensured by calibrating as described in the proceeding Sect. 4 .

\subsection{CCN configuration}

Size-resolved measurements of CCN activity are performed by coupling the $\mathrm{CCNc}$ to a DMA. Figure 2 illustrates the experimental set-up. If the sample aerosol is not dry it is dried using a diffusion drier (e.g. Perma Pure, MD-110). The sample is then charge equilibrated using a Strontium90 or Polonium-210 radioactive source (depending on source availability in a particular project). A quasi-monodisperse size cut is then selected using a DMA. The DMA is operated with a sheath flow of 10 litres per minute and a sample flow of 1 litre per minute. The DMA's sheath flow is dried using a Nafion (Perma Pure, PD-200T-12) drier. The RH and $\mathrm{T}$ of the sample, sheath and sheath excess flows are monitored continuously using capacitive probes (Rotronic, HygroClip) (Williams et al., 2007). The size selected sample is then either split between the $\mathrm{CCNc}$ and a condensation particle counter (CPC, TSI 3010) or to either one of the CPC or $\mathrm{CCNc}$ depending on the chosen configuration.

For calibrations the aerosol is sampled by both the CPC and the CCNc. The sample flow to the CPC is diluted with 0.5 litres per minute of particle free air, to maintain a flow of 1 litre per minute through the DMA. The sample flow is continuously monitored using a differential pressure gauge. The length of the sample lines to the top of the column of the $\mathrm{CCNc}$ the CPC's inlet are matched so that any differences in particle loss are minimised. For ambient measurements, a configuration where either the CPC or the $\mathrm{CCN}$ sampled the size selected aerosol is frequently used. An automated 4-way valve switches between the CCNc and CPC every hour. This allows measurements of the total $\mathrm{CCN}$ number concentration during the hour when it is not connected to the DMA and the configuration then allows measurements of the size-resolved $\mathrm{CCN}$ number $\left(N_{\mathrm{CCN}}\left(S, D_{0}\right)\right)$ and $\mathrm{CN}$ number $\left(N_{\mathrm{CN}}\left(D_{0}\right)\right)$ to be compared, as well as the total CCN concentration. Alternatively the configuration is left the same as for the calibrations and simultaneous $N_{\mathrm{CCN}}\left(S, D_{0}\right)$ and $N_{\mathrm{CN}}\left(D_{0}\right)$ distributions are measured. The $\mathrm{CCNc}$ is operated throughout the experiments described here with a total flow rate of $5 \mathrm{Lmin}^{-1}$, with a 10:1 sheath to sample flow ratio. The CCNc's column was wetted at a rate of $\approx 8 \mathrm{~m} \mathrm{~L} \mathrm{~min}^{-1}$ (the medium flow setting). $T_{1}$ is set to $1 \mathrm{~K}$ above $T_{\text {inlet }}$, the OPC (optical particle counter) $T$ is set to $3 \mathrm{~K}$ above $T_{3}$.

\section{Instrument calibration}

Prior to experiments the performance of the instruments is always characterised and validated. In the case of the HTDMA this means calibrating its DMAs, capacitive RH and $T$ probes and sampling 2 nebulised aerosols of known composition and growth factor. In the case of the $\mathrm{CCNc}$ this means first calibrating the DMA used to size select the sample aerosol, calibrating the CCNc's sample and sheath flows and then calibrating the supersaturation using 2 nebulised aerosols of known composition.

\subsection{DMA calibration}

Both the HTDMA and CCNc rely on DMAs to size select the aerosol sample prior to determination of their hygroscopic growth and CCN activity. It is therefore important to verify that they are sizing correctly. The DMA's sheath flow meters are calibrated using a primary air flow standard (Sensidyne, Gilibrator) and the high voltage supplies are tested to ensure the correct voltage is being set.

The DMAs used to size select the aerosol samples are then calibrated using latex spheres (Duke Scientific). The latex spheres are nebulised and sampled by the DMAs operating in DMPS mode, with over-sampling around the peak. The HTDMA's DMA1 is connected directly to the CPC, whilst the output from the DMA to the CCNc is switched so that only the CPC draws the sample flow (as shown in Fig. 2), by doing this the same operating conditions (most importantly the sheath and aerosol flow rates) are maintained. The distributions are then fitted to determine the size at the peak of the distribution. This is repeated for a series of sizes between $92.5 \mathrm{~nm}$ and $598 \mathrm{~nm}$. A linear regression is then used relate the diameter set by the DMA to the PSL diameter to produce a correction to the DMA sizing (Williams et al., 2007). One of the limitations of these calibrations is that nebulising 
Table 1. DMA PSL calibrations for the DMA supplying the CCNc and the HTDMA's first DMA. The fit error is the difference between the applied linear fit and the measurement.

\begin{tabular}{lccccc}
\hline PSL $(\mathrm{nm})$ & PSL Std. $(\mathrm{nm})$ & DMA $_{\mathrm{CCNc}}(\mathrm{nm})$ & Fit Error $(\mathrm{nm})$ & DMA $_{\text {HTDMA }}(\mathrm{nm})$ & Fit Error $(\mathrm{nm})$ \\
\hline 92 & 7.0 & 94.4 & 1.91 & 92.5 & 0.59 \\
199 & 3.4 & 197 & 1.30 & 201 & 0.91 \\
299 & 4.1 & 296 & 1.50 & 303 & 2.91 \\
596 & 6.5 & 592 & 0.91 & 594 & 1.91 \\
\hline
\end{tabular}

spheres smaller than $\approx 90 \mathrm{~nm}$ is not possible using our standard techniques (Cubison et al., 2005). Therefore calibrations are carried out in the laboratory using an electrospray aerosol generator (TSI, 3480) to produce sub-90 $\mathrm{nm}$ particles of known size for calibration. The electrospray generator can be used to produce particles down to $4 \mathrm{~nm}$ (Chen et al., 1995). Therefore the full size range of the DMAs can be calibrated for in the laboratory prior to deployment in the field ensuring the DMA is operating consistently. Table 1 shows the diameters set by the CCNc's and the HTDMA's first DMA and the corresponding correct PSL diameter. From these calibrations the resulting difference in calibrated versus un-calibrated diameter was up to $4 \mathrm{~nm}$.

\subsection{HTDMA calibration and validation}

The capacitive RH and temperature sensors used to monitor the conditions in the instrument (Cubison et al., 2005) are calibrated against a dew point hygrometer (the same dew point hygrometer used to measure the RH in DMA2) to ensure consistent measurements. The dew point hygrometer is serviced periodically off site to ensure its accuracy. Dry scans are used to calibrate any offset between DMA1 and DMA2 (Gysel et al., 2009; Duplissy et al., 2009). Dry scans are performed with roughly weekly frequency during field projects to ensure the continued performance of the HTDMA and also to define the width of the HTDMA's transfer function (Gysel et al., 2009). For this project the offset between DMA1 and DMA2 was quite large in the range of $9 \%$ to $11 \%$ across the range of selected dry diameters. This demonstrates the importance of validating DMA offset and well as the absolute sizing of the first DMA as described by Gysel et al. (2009). The operation of the HTDMA was verified using ammonium sulphate $\left(\left(\mathrm{NH}_{4}\right)_{2} \mathrm{SO}_{4}\right)$ and sodium chloride $(\mathrm{NaCl})$ test aerosols. The test aerosol $\left(\left(\mathrm{NH}_{4}\right)_{2} \mathrm{SO}_{4}\right.$ and $\mathrm{NaCl}$ in turn) is nebulised (using a TOPAS atomiser). The nebulised aerosol is then dried (to $<15 \% \mathrm{RH}$ ), charge equilibrated and sampled by the HTDMA. The HTDMA then performs a humidogram, whereby the $\mathrm{RH}$ of the aerosol is set to a series of values covering the operational range of the instrument and the growth factor is measured. A dry size of $150 \mathrm{~nm}$ is selected for the calibrations because, above $\approx 100 \mathrm{~nm}$, the Kelvin term is close to 1 (McFiggans et al., 2006) thus reduc-

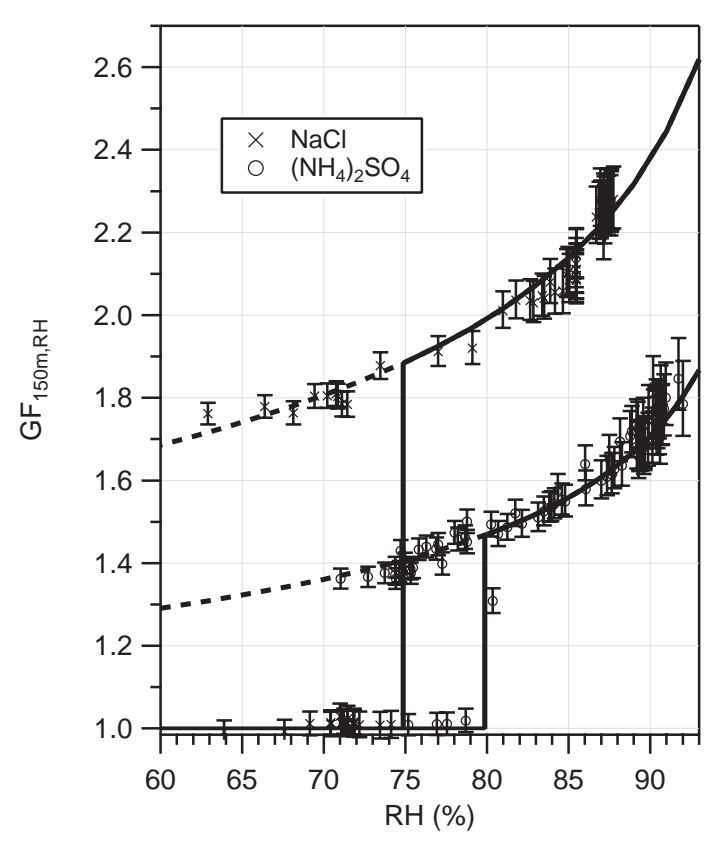

Fig. 3. HTDMA ammonium sulphate and sodium chloride calibrations made during the MAP campaign.

ing artefacts resulting from the sizing uncertainty ensuring straightforward comparison of the data with other measurements and models. The HTDMA used here (Cubison et al., 2005) has the ability to measure effloresced aerosol water uptake. The dry size selected aerosol can be humidified up to the set point RH or it can be passed through a pre-humidifier which increases the RH of the sample to $>90 \%$ before it is reduced to the set point RH in the humidifier. Figure 3 shows these calibrations for the Marine Aerosol Production (MAP) project. From Fig. 3 it can be seen that the agreement between the measured and theoretical growth factors is within the measurement error. The measurement error results from the stability of the TDMA estimated to be \pm 0.02 in growth factor space for a well calibrated TDMA (Duplissy et al., $2009)$ and the uncertainty of the RH measurement $( \pm 1.5 \%$ for the dew point hygrometor). As a result of the operating procedure described the calibration measurements fall within these limits. 


\subsection{CCNc calibration}

The CCNc's sample and sheath flows are calibrated using a primary flow standard (Sensidyne, Gilibrator). The sizing of the OPC is verified by sampling nebulised $1000 \mathrm{~nm}$ latex spheres (Duke Scientific). The CCNc is calibrated using ammonium sulphate and sodium chloride test aerosol generated in the same manner as for the HTDMA calibrations (described in Sect 3). The CCNc is set-up as described in Sect. 3.3. For the calibrations a single size is selected by the DMA and the CCN concentration is measured at a series of supersaturations, simultaneously the total particle number concentration at that size is measured by the $\mathrm{CPC}$. The $\mathrm{CCN}$ and $\mathrm{CN}$ concentrations are then used to calculate the activated fraction $\left(\operatorname{AF}\left(S, D_{0}\right)\right)$ as defined in Eq. 3:

$\mathrm{F}_{\mathrm{A}}\left(S, D_{0}\right)=\frac{N_{\mathrm{CCN}}\left(S, D_{0}\right)}{N_{\mathrm{CN}}\left(D_{0}\right)}$

where $N_{\mathrm{CCN}}\left(S, D_{0}\right)$ is the $\mathrm{CCN}$ number concentration at the set supersaturation $(S)$ and $D_{0}$ and $N_{\mathrm{CN}}\left(D_{0}\right)$ is the number concentration of condensation nuclei $(\mathrm{CN})$ at the selected $D_{0}$. The $\mathrm{F}_{\mathrm{A}}$ is then used to calculate the critical supersaturation $\left(S_{c}\right)$ of the particles at the selected $D_{0} . S_{c}\left(D_{0}\right)$ is defined as the supersaturation at which $\mathrm{F}_{\mathrm{A}}\left(S, D_{0}\right)$ is equal to 0.5 . This definition of $S_{c}\left(D_{0}\right)$ relies on several assumptions which are discussed in Sect. 5.3. In order to define $S_{c}$ as accurately as possible the $S$ at which $\mathrm{F}_{\mathrm{A}}=0.5$ needs to be found. This is achieved by incrementally increasing the setpoint $S$ such that $\mathrm{F}_{\mathrm{A}}$ increases from 0 to 1 . In order that $\mathrm{F}_{\mathrm{A}}$ $=0.5$ is well defined the resolution of the set-point $S$ is increased for $\mathrm{F}_{\mathrm{A}}$ values around 0.5 . Increments in the set-point $S$ of $0.02 \%$ are used (equivalent to steps in $\delta T$ of $\approx 0.02 \mathrm{~K}$ ). An $S$ should be set such that $\mathrm{F}_{\mathrm{A}}=0$, this helps verify there are no leaks. It is also important that the maximum $\mathrm{F}_{\mathrm{A}}$ is measured. If the CPC and OPC are in agreement it should be 1, however there may be a systematic offset resulting from their calibration. Once all reasons for a discrepancy have been removed (e.g. leaks and flow imbalances are perhaps the most likely causes) a correction factor may be applied to the data. The accuracy of most commercial CPCs and OPCs is usually $\pm 10 \%$ so a correction factor to the $\mathrm{F}_{\mathrm{A}}$ is usually no more than $15 \%$. For the example experiments shown here a correction factor of $+4.5 \%$ is applied to the measured $N_{\mathrm{CCN}}$.

It is important define which particles detected by the $\mathrm{CCNc}$ are activated droplets. The $\mathrm{CCN}$ counter measures the size of the particles exiting the supersaturated column using an OPC. In this paper particles of $1 \mu \mathrm{m}$ and above are considered as activated CCN. Lance et al. (2006) suggest a method for determining which droplets sizes in the OPC are $\mathrm{CCN}$, which may offer an improvement. It is expected that particles in the size range sampled will be activated droplets if they are $1 \mu \mathrm{m}$ or greater in diameter when detected in the OPC. This assumption will likely be tested at the lowest $S$ set point $(0.08 \%)$ (Lance et al., 2006). An empirical approach to determine the bin to choose may improve on the method pre- sented here but without knowing the growth kinetics of the sampled aerosol particles it is hard to say if the effect will be large, we assume it will not be for the ambient aerosol. In the case of the calibration aerosol the critical diameter is predicted by the thermodynamic model (ADDEM, Topping et al. (2005a)) as part of the critical supersaturation calculation. The predicted critical diameters for the calibration aerosols are consistent with using $1 \mu \mathrm{m}$ as the cut-off for activated particles down to the lowest set supersaturation.

Figure 4 shows ammonium sulphate calibrations performed during the MAP project. $5 D_{0}$ s were selected (30, $40,50,70$ and $100 \mathrm{~nm}$ ) in order to calibrate across the range of $S$ set by the CCNc during the project. The settling time of each $S$ depends on the size of the temperature change and the direction (downwards steps in $T$ take longer than upwards steps). Settling times of between 5 and 1 minutes were required, therefore each supersaturation set-point was held for 4 to $10 \mathrm{~min}$ to give adequate settling and sampling time. The settling was verified by making sure the $\mathrm{CCN}$ number had stabilised as well as the temperature readings from the CCNc's diagnostics. The total number concentration is kept below 3000 particles per $\mathrm{cm}^{3}$ (by monitoring the CPC measurement) to avoid coincidence errors in the CCNc's OPC. $N_{\mathrm{CCN}}$ and $N_{\mathrm{CN}}$ at each set point are averaged, removing data during the settling period and then used to calculate the activated fraction. A series of supersaturations are set in the $\mathrm{CCN}$ counter to build up an activation spectrum from 0 to 1 as described above. A sigmoid function is then fitted to the data from which the $S$ at which $\mathrm{F}_{\mathrm{A}}=0.5$ is determined. Figure 4 shows the calibrations and fitted sigmoids for ammonium sulphate calibrations performed during the MAP project. Panels a to e in Fig. 4 show the fitted sigmoids (black lines) and with the correction factor of 1.045 applied (grey dashed lines), the correction makes a negligible difference to the derived $S_{c}$. The same procedure is then repeated for the sodium chloride test aerosol, using the same mobility diameters. The mobility diameter calculated by the DMA's software assumes the particles are spherical, however for example sodium chloride particles tend to be cubic. Constant shape correction factors of 1.02 and 1.08 (Rose et al., 2008) are therefore applied to the ammonium sulphate and sodium chloride calibration particles respectively to correct for this.

The results are then compared to their theoretical $S_{c}$ (Topping et al., 2005a,b). Panel $\mathrm{f}$ in Fig. 4 shows the $S_{c}$ derived from the set-point $S$ compared to the theoretical values at each $D_{0}$ for the ammonium sulphate calibration. The same procedure is repeated for the sodium chloride calibrations. The calibrations using the different salts are then compared, if the instrument is operating properly then they should fall on the same line when plotted as set-point versus theoretical supersaturation. Figure 5 shows the sodium chloride and ammonium sulphate calibrations for the MAP project plotted together. Figure 5 illustrates the improvement in the determination of CCNc's centreline superaturation compared to the factory settings. The five supersaturation set-points 

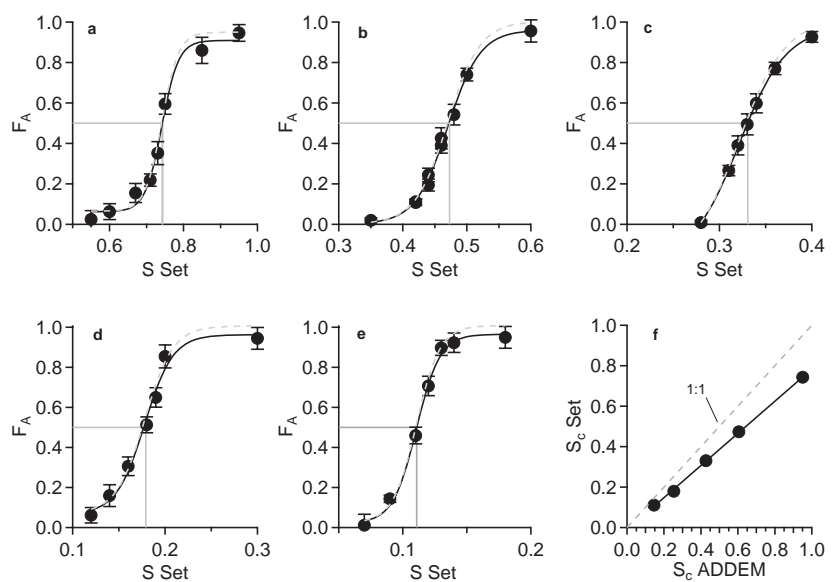

Fig. 4. $\mathrm{CCNc}$ ammonium sulphate calibrations. Panels a-e show AF vs. $S_{\text {set }}$ for $30,40,50,70$ and $100 \mathrm{~nm} D_{0}$ particles made during the MAP campaign. Panel $\mathrm{f}$ shows the set point $S$ vs. theory.

used during the MAP campaign were $0.07,0.15,0.3,0.5$ and $1.0 \%$. The post-calibration values were $0.08,0.18,0.37,0.62$ and $1.28 \%$ respectively,differences of between 0.01 and 0.28 $\%$.

\subsection{Theory}

It is only possible to accurately calibrate the $\mathrm{CCN}$ counter supersaturations and validate the operation of the HTDMA using a suitably accurate thermodynamic model with known test aerosol. The state of the science Aerosol Diameter Dependent Equilibrium Model (ADDEM) as described under subsaturated conditions in Topping et al. (2005a) and for supersaturated conditions in Rissman et al. (2007) is used. Assuming the inorganic salt test aerosol reaches its equilibrium size in the HTDMA and activated droplets reach their critical diameter in the $\mathrm{CCNc}$, ADDEM can accurately predict the $\mathrm{CCN}$ activity and hygroscopic growth factors of the calibration aerosol within the instrument resolutions. Because the $\mathrm{CCNc}$ uses a temperature gradient to generate a supersaturation, choosing a temperature to run the model at is not straightforward. In general, for calibrations, the model predictions at $298.15 \mathrm{~K}$ were used. A more detailed study using a model of the droplet growth inside the $\mathrm{CCNc}$ might be able to back out a slightly more accurate calibration, by calculating the exact point in the $\mathrm{CCNc}$ where the droplet activated. However this would rely on knowledge of the absolute temperature inside the column and would be inconsistent with our approach. The variability in $S_{c}$ across the $T$ investigated is sufficiently small to ignore $( \pm 5 \%$ at $1 \% S$ reducing to \pm $1 \%$ at $0.01 \% S$ ) without biasing the results significantly.

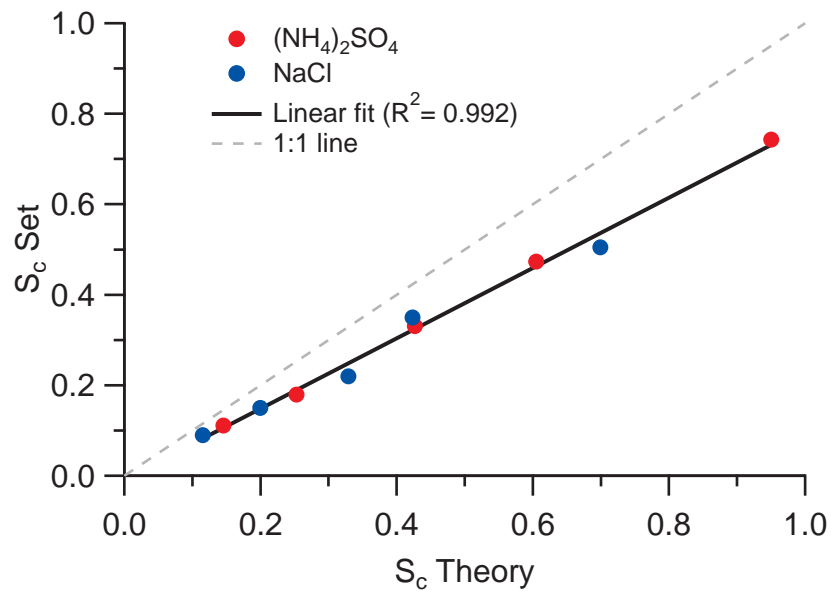

Fig. 5. CCN ammonium sulphate and sodium chloride calibrations from the MAP campaign. Set point vs. theoretical $S_{c}$.

\section{Data analysis}

\subsection{HTDMA data analysis}

A detailed description of the HTDMA data analysis procedure is described by (Gysel et al., 2009) so only a brief outline is given here. Dry scans are performed regularly (at least once a week during continuous operation and at the start and end of the measurement period), so the DMA offset and the system transfer function can be corrected for. The raw data is then processed according to the procedure and inversion routine described by Gysel et al. (2009).

\subsection{DMPS-CCNc data analysis}

In the DMPS-CCN mode of operation the DMPS is used to supply the $\mathrm{CCN}$ counter with an aerosol sample at a series of mobilities. This enables $\mathrm{CCN}$ number size distributions to be generated. The $\mathrm{CCN}$ distributions are then used to calculate $\mathrm{F}_{\mathrm{A}}\left(S, D_{0}\right)$. The data are obtained and analysed as follows:

\subsubsection{Raw data}

The aerosol is sampled by the $\mathrm{CCN}$ and $\mathrm{CN}$ counters as described in Sect. 3. This generates raw $\mathrm{CCN}$ and $\mathrm{CN}$ number size distributions. The first $6 \mathrm{~s}$ of data at each mobility is discarded to allow the instruments to settle. The remaining $18 \mathrm{~s}$ of data at each diameter is then averaged. Figure 6 shows an example of raw and averaged raw $\mathrm{CCN}$ and $\mathrm{CN}$ number size distributions for nebulised sodium chloride aerosol.

\subsubsection{Multi-charge correction}

The raw distributions are corrected for the effects of multiply charged particles as follows. Throughout these calculations 


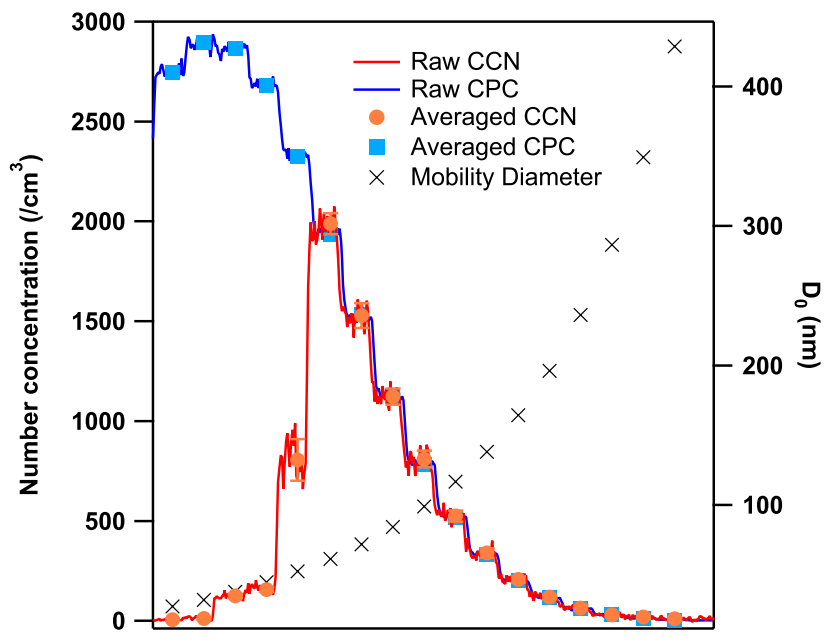

Fig. 6. Example DMPS-CCN distribution of nebulised sodium chloride aerosol at $0.26 \%$ supersaturation. The blue squares show the averaged $N_{\mathrm{CN}}$, the orange squares show the averaged $N_{\mathrm{CCN}}$. The crosses indicate the mobility diameter. The dashed lines show the raw data.

the DMA transfer function is assumed to be ideal (Alofs and Balakumar, 1982) that is; triangular with a half width of:

$\delta Z=\frac{Q_{a}}{2 \pi L V} \ln (r)$

where $\delta Z$ is the half width, $Q_{a}$ is the sheath flow, $L$ is the length of the DMA's central rod, $V$ is the voltage applied to the DMA's anode and $r$ is the ratio of DMAs outer cylinder inner radius to the radius of the central rod. The precise shape of the transfer function is not important for the proceeding data analysis provided it is symmetrical. The AF is used to derive $S_{c}$, so diffusional broadening for example will be cancelled out when $N_{\mathrm{CCN}}\left(S, D_{0}\right)$ and $N_{\mathrm{CN}}\left(D_{0}\right)$ are divided.

The charging probabilities at each selected mobility diameter are calculated (Wiedensohler, 1988). The assumption is then made that particles detected by the CPC at the lowest mobility are all singly charged. This appears to be a good assumption in the studies presented here as closed size distributions are observed i.e. at the largest diameter the number tends to zero. As noted by Petters et al. (2007) this does mean that $\mathrm{CCN}$ measurements are required up to lower mobilities than might otherwise be of interest. The number of particles detected at the smallest mobility is then divided by its single charge probability to calculate the actual particle number. This assumption is repeated for increasing mobilities until their mobility is at least twice that of the lowest mobility $\left(Z_{p \text { min }}\right)$. At this point doubly charged particles can be accounted for and similarly, for triply charged particles once the particle mobility is 3 times the smallest mobility. The number of doubly and triply charged particles are subtracted from the total number measured $\left(N^{\prime}\right)$ at each mobility to give

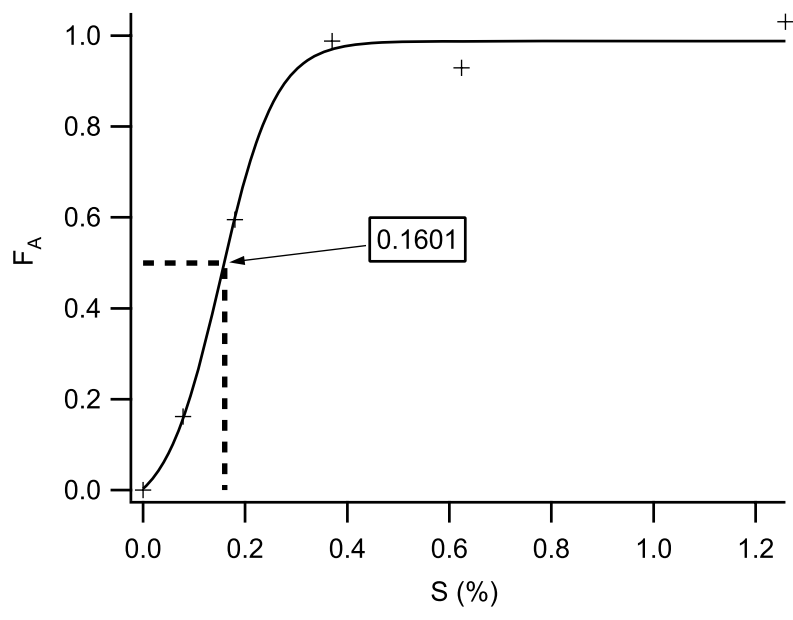

Fig. 7. Example plot of $\mathrm{F}_{\mathrm{A}}$ vs. $S$, with a sigmoid fit used to determine $S_{c}$ measured during the MAP campaign.

the number of singly charged particles. Once the number of singly charged particles is known, the total number is calculated by dividing by the single charging probability of that diameter. The multi-charge correction can be described according to:

$$
\begin{aligned}
& N_{S}\left(Z_{p}\right)=\frac{N\left(Z_{p}\right)}{\epsilon_{S}\left(Z_{p}\right)} \\
& N_{\mathrm{D}}\left(Z_{p}\right)=\frac{N\left(Z_{p} / 2\right)}{\epsilon_{D}\left(Z_{p} / 2\right)} \\
& N_{\mathrm{T}}\left(Z_{p}\right)=\frac{N\left(Z_{p} / 3\right)}{\epsilon_{T}\left(Z_{p} / 3\right)}
\end{aligned}
$$

when $: Z_{p}<\frac{Z_{p \min }}{2}$

$$
N\left(Z_{p}\right)=\frac{N^{\prime}\left(Z_{p}\right)}{\epsilon_{S}\left(Z_{p}\right)}
$$

when $: \frac{Z_{p \min }}{3}<Z_{p} \leq \frac{Z_{p \min }}{2}$

$N\left(Z_{p}\right)=\frac{N^{\prime}\left(Z_{p}\right)-N_{\mathrm{D}}}{\epsilon_{S}\left(Z_{p}\right)}$

when $: Z_{p} \geq \frac{Z_{p \min }}{3}$

$N\left(Z_{p}\right)=\frac{N^{\prime}\left(Z_{p}\right)-N_{\mathrm{D}}-N_{\mathrm{T}}}{\epsilon_{S}\left(Z_{p}\right)}$

where $N_{\mathrm{S}}$ is the number of singly charged particles, $N_{\mathrm{D}}$ is the number of doubly charged particles, $N_{\mathrm{T}}$ is the number of triply charged particles, $\epsilon_{\mathrm{S}}$ is the single charging probability, $\epsilon_{\mathrm{D}}$ is the double charging probability and $\epsilon_{\mathrm{T}}$ is the triple charging probability. Both the $\mathrm{CCN}$ and $\mathrm{CN}$ number size distributions can be calculated using this method. 


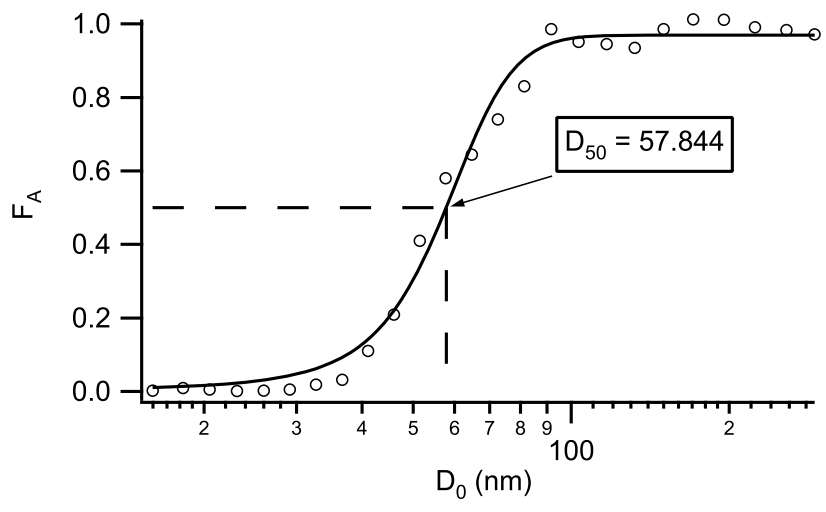

Fig. 8. Example plot of $\mathrm{F}_{\mathrm{A}}$ vs. $D_{0}$, with a sigmoid fit used to determine $D_{50}$ measured during the MAP campaign at $0.37 \%$ supersaturation.

\subsubsection{Deriving $S_{c}$}

A method for calculating the critical supersaturation from the measured $\mathrm{CCN}$ and $\mathrm{CN}$ number size distributions is now described. The errors associated with each of these steps and there propagation is described in detail by Irwin et al. (2010). Firstly the charge corrected $\mathrm{CCN}$ and $\mathrm{CN}$ number size distribution to calculate $\mathrm{F}_{\mathrm{A}}\left(S, D_{0}\right)$. The activated fraction is then used to derive $S_{c}$. In this analysis it is assumed that when $\mathrm{F}_{\mathrm{A}}\left(S, D_{0}\right)$ equals 0.5 then $S$ is equal to $S_{c}$, i.e. all the particles with diameters up to $D_{0}$ under the DMA transfer function are activated CCN at this $S$. The work presented here uses two methods to calculate $S_{c}$ using the $\mathrm{CCN}$ and $\mathrm{CN}$ number size distributions from the DMPS-CCN set-up. One method is to plot $\mathrm{F}_{\mathrm{A}}\left(S, D_{0}\right)$ at each of the supersaturations set by the $\mathrm{CCN}$ counter. A sigmoid fit function is then applied to data to determine the supersaturation at which $50 \%$ of the particles are activated, which has been defined as the $S_{c}$. This method has the advantage that the $D_{0}$ is held constant, but the disadvantage that only a limited number of supersaturations (5) are available to fit the data. Figure 7 shows an example of such a fit for the data measured during the MAP cruise. Alternatively a sigmoid fit of activated fraction vs. diameter can be made. The fit function is then used to determine the $D_{50}$, the diameter at which $50 \%$ of the particles activate at a given supersaturation setting. Thus $\mathrm{F}_{\mathrm{A}}\left(S, D_{0}=D_{50}\right)=0.5$ and $S=S_{c}$ for $D_{0}=D_{50}$. The $D_{50}$ method has the advantage that it is constrained by more data points than the supersaturation fit, however $D_{0}$ is variable so the behaviour at a constant diameter is not captured directly. Figure 8 shows an example of a $D_{50}$ derivation for the data measured during the MAP cruise. For the MAP project $\mathrm{F}_{\mathrm{A}}$ vs. $S$ plots are used to derived $S_{c}$, so that $D_{0}$ remains constant. The $D_{50}$ method is applied only to check data consistency.
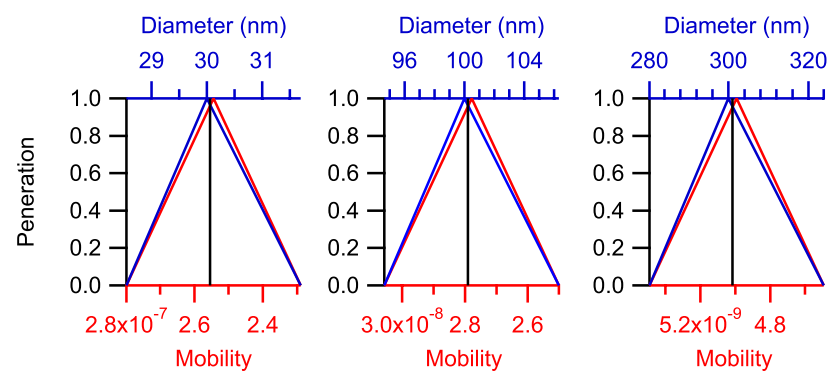

Fig. 9. Ideal mobility and diameter transfer functions for 30, 100 \& $300 \mathrm{~nm}$ particles. The vertical lines illustrate the difference between the selected mobility diameter and the mobility diameter at $50 \%$ of the area of the transfer function.

\subsection{Defining $S_{c}$}

The definition of $S_{c}$ used in these analyses relies on assumptions about the system's transfer function, (the penetration probability of a particle of a given size through the instrument) and the mixing state of the sample aerosol.

\subsubsection{Transfer function}

It is assumed that the system's particle mobility transfer function is symmetrical and that the aerosol is internally mixed with respect to its $\mathrm{CCN}$ activity i.e. the particle penetration efficiency through the DMA, CCN counter and connecting tubing is symmetrical about the mobility set by the DMA. The ideal mobility diameter DMA transfer function is slightly asymmetrical. However this translates to a very small difference in the actual diameter at $50 \%$ activation (Rose et al., 2008), but can be taken into account for completeness (Fig. 9 illustrates the correction required for 30 , 100 and $300 \mathrm{~nm}$ particles, the range of sizes typically sampled). Size dependent losses in the system could also cause a bias in the transfer function, this is minimised by maintaining a sheath flow to sample flow ratio of 10:1, ensuring the width of the transfer function is narrow enough that losses will not be significantly different across its width.

\subsubsection{Mixing state}

The mixing state of the aerosol is a potentially important factor. If the aerosol is externally mixed then the supersaturation at AF equals 0.5 may not represent the $S_{c}$ well. For example if there are 2 distinct particle hygroscopicities of equal number fraction when $\mathrm{F}_{\mathrm{A}}=0.5$ the supersaturation will fall between their actual $S_{c}$. It is therefore important to verify that the sample is suitable for the analysis methods described. One way to do this is to examine the hygroscopic growth factor distributions for the aerosol being sampled. If the growth factor distributions show that the aerosol is largely internally mixed i.e. the particles at anyone size are of the 


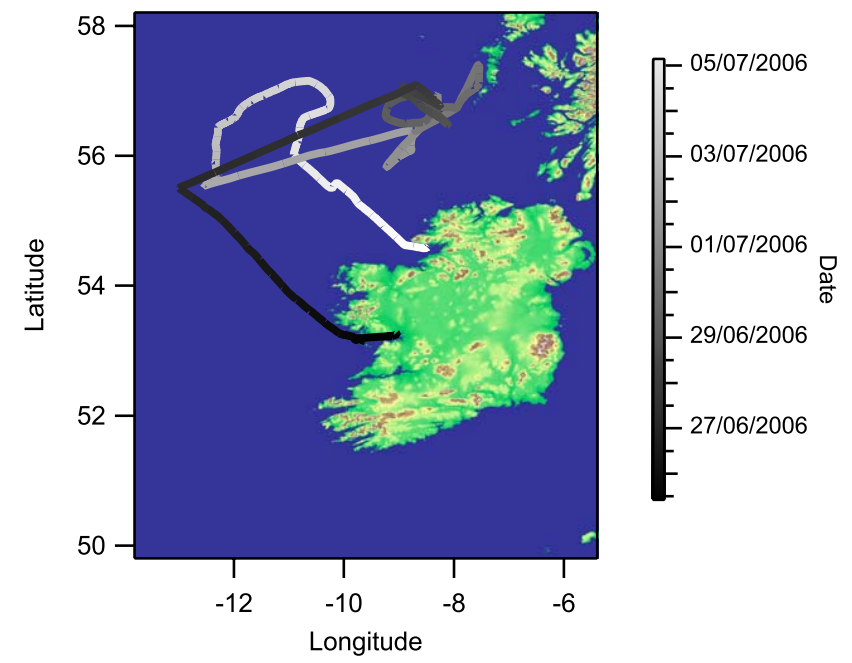

Fig. 10. The Celtic Explorer cruise track between 26th June 2006 and 5th July 2006 during the MAP campaign.

same composition then $S_{c}$ can be calculated using the methods described. As CCN activity is more sensitive to the particle dry diameter than sub-saturated hygroscopic growth, this assumption should hold, e.g. it is unlikely an aerosol which appears internally mixed at $90 \%$ RH will have widely varying $\mathrm{CCN}$ behaviour at a single dry size. If the growth factor distributions show that the aerosol is externally mixed then a different analysis approach must be adopted.

\section{Example of operation in the field}

The combination of HTDMA and CCNc was deployed in the field as described in this paper on the Celtic Explorer during the MAP campaign for 2 weeks in June and July 2006. The marine environment is a source of primary and secondary aerosol which significantly impacts upon the global radiative budget. The potential role of biological aerosol sources in the marine environment has been highlighted (O'Dowd et al., 2004). Therefore a quantitative understanding of the mechanisms via which marine aerosol is formed and its properties is required. The Celtic Explorer provided a ship-borne platform for the in-situ study of Marine Aerosol in and around biologically active waters. Figure 10 shows the ship's cruise track. The area surveyed was off the West coast of Ireland in the North-East Atlantic Ocean. The air masses sampled were of Marine origin from over the open ocean as well as some periods where the air had passed over continental Ireland and coastal areas.

Figure 11 shows the number size distribution measured using a DMPS (Williams et al., 2007). The number size distribution is mostly dominated by particles in the Aitkin and Accumulation size ranges. When the total (integrated) number concentration is less than $\approx 500 \mathrm{~cm}^{-3}$ the number of Aitkin

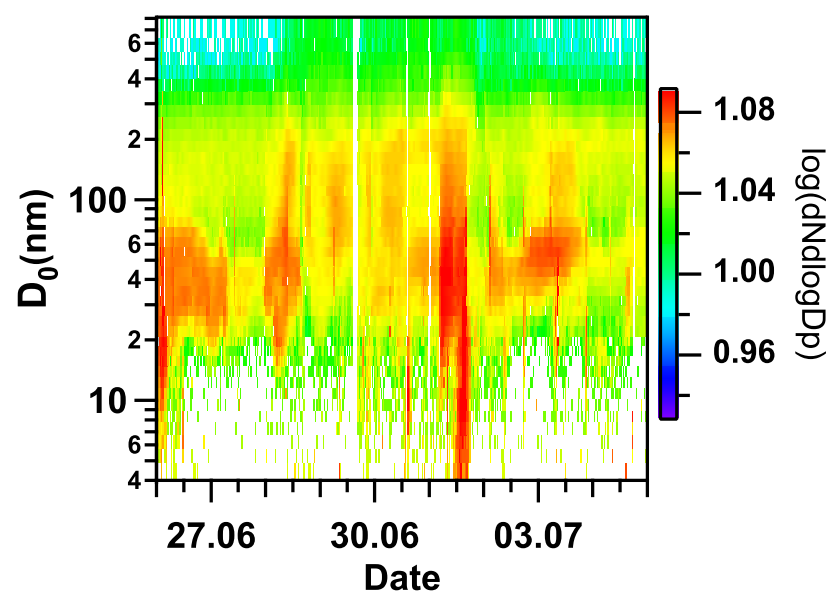

Fig. 11. The aerosol particle number size distribution measured during the MAP Celtic explorer campaign.

and Accumulation sized particles is similar and the resulting bi-modal spectrum is typical of a clean marine environment (Hoppel et al., 1986). Frequently the air being sampled is characterised by higher number concentrations of the order of $\approx 10^{3} \mathrm{~cm}^{-3}$. In comparison to the "clean" conditions the concentration in the Aitkin mode is most numerous. Only occasionally are significant numbers of sub-10nm particles observed, during more polluted episodes.

Measurements of the hygroscopic growth factor were performed at $90 \% \mathrm{RH}$ for $D_{0} s$ of 30, 50, 100, 150 and $200 \mathrm{~nm}$. The size-resolved CCN activation was measured at 5 set supersaturations for $D_{0} s$ between 30 and $300 \mathrm{~nm}$. The 5 calibrated supersaturations were $0.08,0.18,0.37,0.62$ and $1.26 \%$.

\subsection{HTDMA measurements}

Figure 12 shows the time series of the hygroscopic growth factor distributions retrieved from the HTDMA averaged over $4 \mathrm{~h}$ intervals. The grey areas on Fig. 12 indicate periods where the HTDMA was being calibrated. The distribution of hygroscopic growth factors at each $D_{0} s$ showed little evidence of external mixing with respect to water uptake, with most of the humidified aerosol contained within a single mode. Exceptionally, a second relatively hydrophobic mode appears, most likely attributable to localized primary emissions from passing ships. The mean hygroscopic growth factor of the dominant mode varied between 1.3 and 1.8; particles with smaller dry diameters showing slightly lower growth factors. The small decrease in the growth factor of the aerosol with decreasing $D_{0} s$ which can be attributed to the Kelvin effect indicates that the composition of the aerosol may be relatively homogeneous across the measured dry diameter range. 


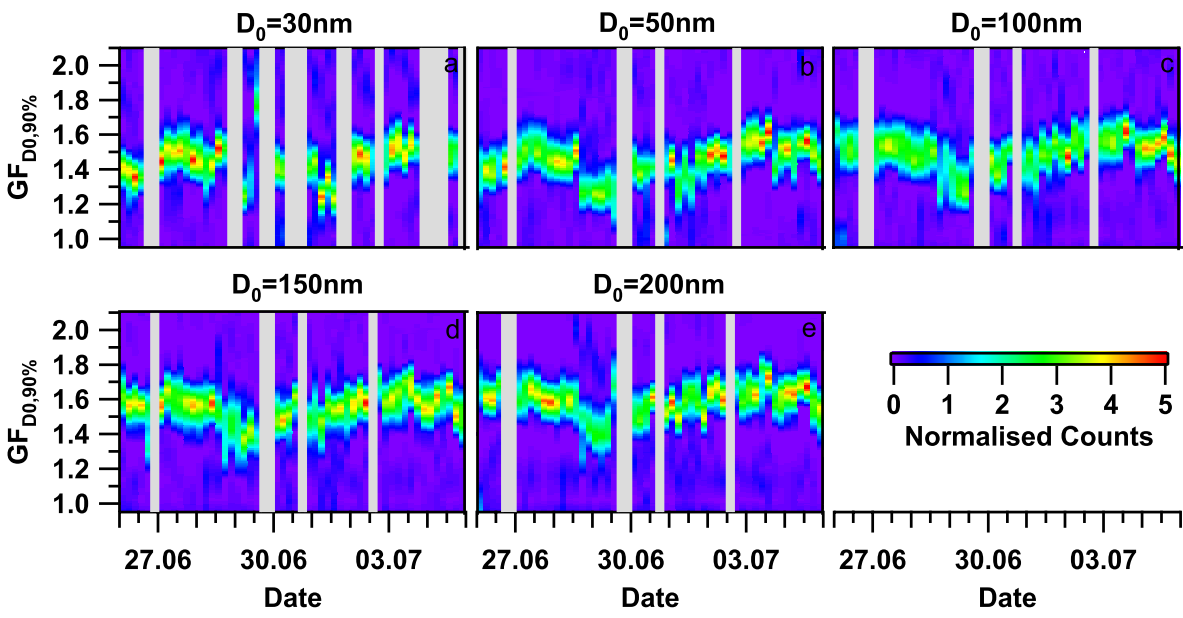

Fig. 12. Time series of the hygroscopic growth factor distributions measured during the MAP campaign, at the 5 set $D_{0}$ in panels a to e.

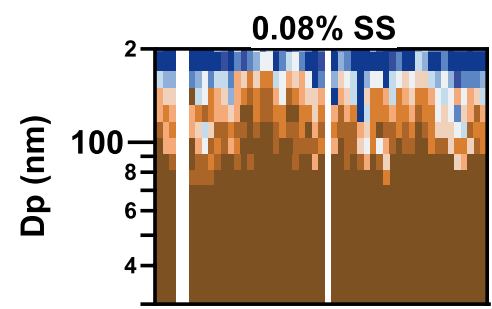

$0.62 \%$ SS

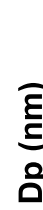

$0.18 \%$ SS

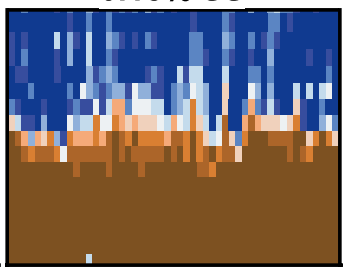

$1.26 \%$ SS

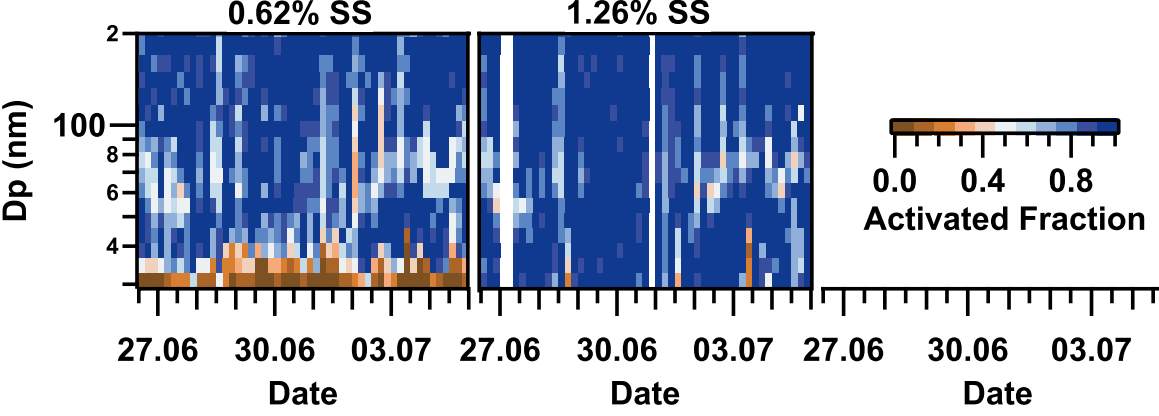

$0.37 \%$ SS

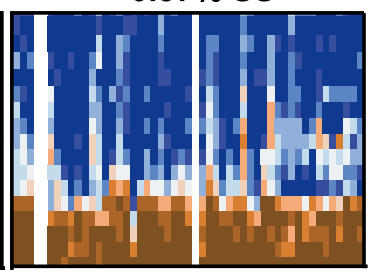

$\begin{array}{lll}0.0 & 0.4 & 0.8\end{array}$

Activated Fraction

Date

Fig. 13. Time series of $\mathrm{F}_{\mathrm{A}}\left(S, D_{0}\right)$ at each of the 5 supersaturations during the MAP project.

The observation of a more hygroscopic mode $\left(\mathrm{GF}_{D 0,90}\right.$ of $\approx 1.5-1.8$ ) persisting throughout the measurement period is common to most HTDMA observations made in the marine environment (Swietlicki et al., 2008) including the North East Atlantic (Swietlicki et al., 2000). The growth factor of the more hygroscopic mode is consistent with an aerosol the composition of which is dominated by sulphate. For example a pure $100 \mathrm{~nm}$ diameter ammonium sulphate aerosol particle has a growth factor of 1.70 at $90 \% \mathrm{RH}$. However, the resolution of the HTDMA limits exact determination of the aerosol composition. Internal mixtures of more hygroscopic solutes for example sodium chloride or ammonium bisulphate combined with less hygroscopic compounds such as organics could result in growth factors in the more hygroscopic range.
A very hygroscopic growth factor mode $\left(\mathrm{GF}_{D 0,90}>\approx 1.8\right)$ is very rarely observed. A very hygroscopic mode is associated with sea-salt (sodium chloride) aerosol. This indicates that there was not a large amount of sea-salt aerosol being produced. It may also be that sea spray aerosol is processed into an internal mixture or other compounds (Svenningsson, 2007) which cannot be resolved by the HTDMA.

\subsection{CCNc measurements}

Figure 13 shows $\mathrm{F}_{\mathrm{A}}\left(S, D_{0}\right)$ measured at the 5 set supersaturations. $\mathrm{F}_{\mathrm{A}}\left(S, D_{0}\right)$ is used to calculate $S_{c}$ using the two methods outlined previously; by fitting $\mathrm{F}_{\mathrm{A}}\left(S, D_{0}\right)$ against $D_{0}$ to derive $D_{50}$ and hence $S_{c}$, and by fitting $\mathrm{F}_{\mathrm{A}}\left(S, D_{0}\right)$ against the 5 set supersaturations to derive $S_{c}$. Figure 14 shows the time 
Table 2. Average $\kappa$ values and standard deviations (std.) from the project, computed assuming the surface tension is that of pure water. $D_{50}$ denotes $\mathrm{F}_{\mathrm{A}}$ vs. $D_{0}$ fits and $S$ Scan denotes $\mathrm{F}_{\mathrm{A}}$ vs. $S$ fits.

\begin{tabular}{lcccc}
\hline Method & $\kappa\left(S, D_{0}\right)$ & $\kappa$ & $\kappa$ & $\kappa$ \\
\hline$D_{50}$ & $0.83(0.08 \%)$ & $0.82(0.18 \%)$ & $0.85(0.37 \%)$ & $0.79(0.62 \%)$ \\
std. & 0.33 & 0.28 & 0.49 & 0.45 \\
$S$ Scan & $0.89(30 \mathrm{~nm})$ & $0.80(50 \mathrm{~nm})$ & $0.76(100 \mathrm{~m})$ & $0.83(150 \mathrm{~nm})$ \\
std. & 0.35 & 0.4 & 0.37 & 0.43 \\
HTDMA & 0.40 & 0.33 & 0.31 & 0.32 \\
std. & 0.09 & 0.06 & 0.05 & 0.05 \\
\hline
\end{tabular}

series of $D_{50}$ at the 5 set supersaturations. Figure 15 shows the time series of $S_{c}$ derived by fitting $\mathrm{F}_{\mathrm{A}}\left(S, D_{0}\right)$ against $S$. The CCN data is averaged onto a the same $4 \mathrm{~h}$ time base as the HTDMA's data. The derived $S_{c} s$ generally fall between those of ammonium sulphate and sodium chloride. The black boxes in the Figs. 14 and 15 highlight data points which have been fitted outside the operational range of the instrument. When the $D_{50}$ is below the smallest size set by the DMA ( $30 \mathrm{~nm}$ ) or the $S_{c}$ from the fitted sigmoid is substantially below the lowest $S$ set by the CCN counter.

In order to ensure that the CCNc's calibrations remain valid the operational conditions during the experiment were kept are close to the calibration conditions as possible. The inlet temperature varied from $296.4 \mathrm{~K}$ to $299.5 \mathrm{~K}$ (except for a $5 \mathrm{~h}$ period when it dropped to $295.3 \mathrm{~K}$ ) and the sample pressure varied from $1001 \mathrm{mb}$ to $1026 \mathrm{mb}$. Therefore according to the calculations of (Roberts and Nenes, 2005) the change in centreline supersaturation for these variations will be small $\approx 0.01 \%$ and will not bias the measurements. A comparison between the $S_{c}$ values derived from the two methods described in this paper can be made by comparing the $\kappa$ parameters (Petters and Kreidenweis, 2007) derived from the different values of $S_{c}$. Table 2 shows the $\kappa$ values from the two methods of deriving $S_{c}$. The $\kappa$ values for the 2 methods of deriving $S_{c}$ are consistent, covering a similar range of value.

The hygroscopic growth factors were also used to calculate $\kappa . \kappa$ derived from the DMA-CCN can be compared with that from the HTDMA to examine the relationship between hygroscopic growth and CCN activity. Comparing the $\kappa$ values derived from the HTDMA and the CCNc we see from Table 2 that on average the $\kappa$ values from the $\mathrm{CCNc}$ are higher. There is also more variability in the $\mathrm{CCNc}$ derived $\kappa$ values. The difference in the derived values may be due to an instrument bias, however as demonstrated a rigorous operational and calibration procedure was followed. The calibration aerosol used for the $\mathrm{CCNc}$ covered the operational supersaturation range and produced consistent results throughout the campaign. The same test aerosol measured by the HTMDA produced results consistent with theory. It may be therefore that it is the composition of the aerosol causing the

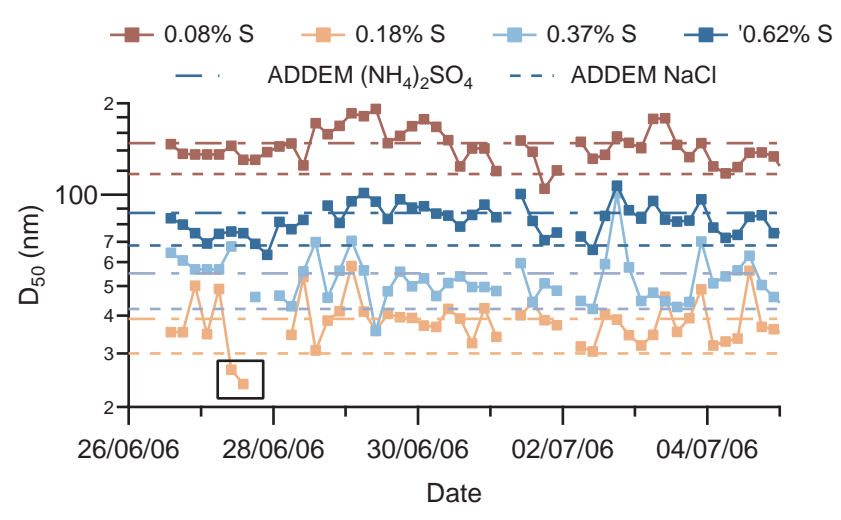

Fig. 14. Time series of $D_{50}$ at $0.08,0.18,0.37$ and $0.62 \% \mathrm{~S}$ measured during the MAP campaign. The dashed lines show the theoretical $D_{50}$ at each of the supersaturations for ammonium sulphate and sodium chloride.

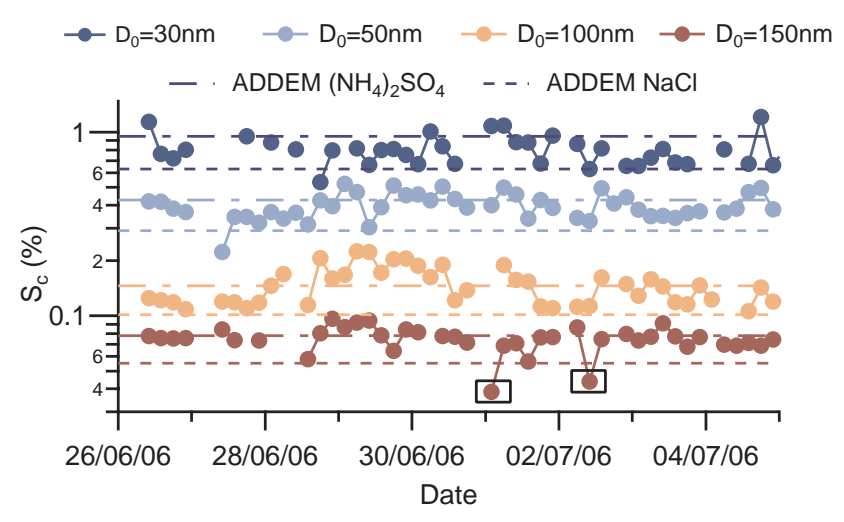

Fig. 15. Time series of $S_{c}$ at 30, 50, 100 and 150nm measured during the MAP campaign. The dashed lines show the theoretical $S_{c}$ at each of the supersaturations for ammonium sulphate and sodium chloride.

difference. Several properties of the aerosol could explain the difference. The non-idealality of the solution (i.e. activity coefficient) might change significantly between $90 \% \mathrm{RH}$ and the point of activation. The Kelvin term may not be accurately represented assuming the surface tension is equal to that of water. The increase in the importance of the Kelvin term at higher RHs means that if there are surface active compounds in the aerosol a reduction in the surface tension may result in an apparent increase in $\kappa$ at the point of activation. Sparingly soluble compounds in the aerosol particles could also explain the differences. Solutes which are solid at $90 \%$ RH but which deliquesce between $90 \%$ and the point of $\mathrm{CCN}$ activation would lead to an increase in the derived $\kappa$. Further work is needed to fully investigate the significance of the results beyond the scope of this paper. 


\section{Discussion and conclusions}

We have demonstrated a robust method of repeatedly calibrating a field deployable system of CCN and HTDMA to determine the size-resolved hygroscopic growth and $\mathrm{CCN}$ activity of atmospheric aerosols. The instruments are shown to be accurately calibrated and their performance is verified. The operation of the instruments is then demonstrated in the field where the properties of the aerosol sampled are not known a-priori and the data analysis procedures (including correction factors) are described.

Accurate calibrations are vital to ensure reliable measurement of hygroscopic growth and CCN activity. The performance of the HTDMA is validated with measurements of ammonium sulphate and sodium chloride test aerosols. The $\mathrm{RH}$ and the growth factor measured by the HTDMA agree with the state-of-the-science theoretical description within measurement uncertainty. Thus operation of the HTDMA is verified and no $\mathrm{RH}$ correction factor is required. The $\mathrm{CCNc}$ requires calibrating in order to determine the $S$ to which the aerosol sample is exposed to. The $S$ at the column centreline for a given $\delta T$ is inferred from measurements of test aerosols. An accurate Köhler model is applied to determine the theoretical supersaturations on which the calibration is based. For the CCNc's measurements to be valid it must be assumed that the temperatures in the column are set repeatedly to the same values for each set point $T$, over the course of an experiment lasting $\approx 2$ weeks during which the $\mathrm{CCNc}$ is in continuous operation, this appears to be the case. What is not assumed is that the centreline $S$ corresponds directly to the set point $T \mathrm{~s}$. For the experiments presented here the temperature of the sample aerosol is maintained close to $20^{\circ} \mathrm{C}$, this ensures the absolute $T$ s do not vary significantly when setting the same supersaturation. All the measurements were performed at sea level so pressure variation was minimised.

For both the HTDMA validation and $\mathrm{CCNc}$ calibration two test aerosols were used. By using separate standards, bias as a result of factors other than the effective $\mathrm{RH}$ and $S$ such as the DMA's mis-sizing significantly can be discounted as this would cause different correction factors for the 2 test aerosols.

The derivation of $S_{c}$ from the CCNc relies on the assumptions described previously. These may limit the applicability of the technique in certain environments. In particular the mixing state may affect the derivation of $S_{c}$. The simultaneous HTDMA measurements allow the mixing state to be assessed.

Acknowledgements. Nicholas Good was supported by a NERC studentship (NER/S/A/2005/13221).

Edited by: S. Buehler

\section{References}

Allan, J. D., Baumgardner, D., Raga, G. B., Mayol-Bracero, O. L., Morales-García, F., García-García, F., Montero-Martínez, G., Borrmann, S., Schneider, J., Mertes, S., Walter, S., Gysel, M., Dusek, U., Frank, G. P., and Krämer, M.: Clouds and aerosols in Puerto Rico - a new evaluation, Atmos. Chem. Phys., 8, 12931309, doi:10.5194/acp-8-1293-2008, 2008.

Alofs, D. J. and Balakumar, P.: Inversion to Obtain Aerosol Size Distributions from Measurements with a Differential Mobility Analyzer, J. Aerosol Sci., 13, 513-527, 1982.

Chen, D. R., Pui, D. Y. H., and Kaufman, S. L.: Electrospraying of Conducting Liquids for Monodisperse Aerosol Generation in the $4 \mathrm{Nm}$ to 1.8 Mu-M Diameter Range, J. Aerosol Sci., 26, 963 977, 1995.

Cubison, M. J., Coe, H., and Gysel, M.: A modified hygroscopic tandem DMA and a data retrieval method based on optimal estimation, J. Aerosol Sci., 36, 846-865, doi:10.1016/j.jaerosci.2004.11.009, 2005.

Duplissy, J., Gysel, M., Sjogren, S., Meyer, N., Good, N., Kammermann, L., Michaud, V., Weigel, R., Martins dos Santos, S., Gruening, C., Villani, P., Laj, P., Sellegri, K., Metzger, A., McFiggans, G. B., Wehrle, G., Richter, R., Dommen, J., Ristovski, Z., Baltensperger, U., and Weingartner, E.: Intercomparison study of six HTDMAs: results and recommendations, Atmos. Meas. Tech., 2, 363-378, doi:10.5194/amt-2-363-2009, 2009.

Fuchs, N. A.: On the Stationary Charge Distribution on Aerosol Particles in a Bipolar Ionic Atmosphere, Pure. Appl. Geophys., 56, 185-193, 1963.

Gunthe, S. S., King, S. M., Rose, D., Chen, Q., Roldin, P., Farmer, D. K., Jimenez, J. L., Artaxo, P., Andreae, M. O., Martin, S. T., and Pöschl, U.: Cloud condensation nuclei in pristine tropical rainforest air of Amazonia: size-resolved measurements and modeling of atmospheric aerosol composition and CCN activity, Atmos. Chem. Phys., 9, 7551-7575, doi:10.5194/acp-9-75512009, 2009.

Gysel, M., McFiggans, G., and Coe, H.: Inversion of tandem differential mobility analyser (TDMA) measurements, J. Aerosol Sci., 40, 134-151, doi:10.1016/j.jaerosci.2008.07.013, 2009.

Hoppel, W. A., Frick, G. M., and Larson, R. E.: Effect of Nonprecipitating Clouds on the Aerosol Size Distribution in the Marine Boundary-Layer, Geophys, Res. Lett., 125-128, 1986.

Irwin, M., Allan, J., and McFiggans, G.: Evaluation of errors in derived data products from water uptake measurements of atmospheric particulatesl, Atmos. Meas. Tech. Discus., in press, 2010.

Juranyi, Z., Gysel, M., Duplissy, J., Weingartner, E., Tritscher, T., Dommen, J., Henning, S., Ziese, M., Kiselev, A., Stratmann, F. George, I., and Baltensperger, U.: Influence of gas-to-particle partitioning on the hygroscopic and droplet activation behaviour of alpha-pinene secondary organic aerosol, Phys. Chem. Chem. Phys., 11, 8091-8097, 2009.

Keady, P., Quant, F., and Sem, G.: Differential mobility particle sizer: a new instrument for high-resolution aerosol size distribution measurement below $1 \mu \mathrm{m}$., TSI Quarterly, 9, 3-11, 1983.

King, S. M., Rosenoern, T., Shilling, J. E., Chen, Q., and Martin, S. T.: Increased cloud activation potential of secondary organic aerosol for atmospheric mass loadings, Atmos. Chem. Phys., 9, 2959-2971, doi:10.5194/acp-9-2959-2009, 2009.

Knutson, E. O. and Whitby, K. T.: Aerosol Classification by Electric Mobility: Apparatus, Theory, and Applications, J. Aerosol 
Sci., 6, 443-451, 1975.

Lance, S., Medina, J., Smith, J. N., and Nenes, A.: Mapping the operation of the DMT Continuous Flow CCN counter, Aerosol Sci. Tech., 40, 242-254, 2006.

Liu, B. Y. H., Pui, D. Y. H., Whitby, K. T., Kittelson, D. B., Kousaka, Y., and McKenzie, R. L.: Aerosol Mobility Chromatograph - New Detector for Sulfuric-Acid Aerosols, Atmos. Environ., 12, 99-104, 1978.

Maricq, M. M.: On the Electrical Charge of Motor Vehicle Exhaust Particles, J. Aerosol Sci., 37, 858-874, doi:10.1016/j.jaerosci.2005.08.003, 2006.

McFiggans, G., Artaxo, P., Baltensperger, U., Coe, H., Facchini, M. C., Feingold, G., Fuzzi, S., Gysel, M., Laaksonen, A., Lohmann, U., Mentel, T. F., Murphy, D. M., O’Dowd, C. D., Snider, J. R., and Weingartner, E.: The effect of physical and chemical aerosol properties on warm cloud droplet activation, Atmos. Chem. Phys., 6, 2593-2649, doi:10.5194/acp-6-2593-2006, 2006.

Nenes, A., Chuang, P. Y., Flagan, R. C., and Seinfeld, J. H.: A theoretical analysis of cloud condensation nucleus (CCN) instruments, J.Geophys. Res. [Atmos], 106, 3449-3474, 2001.

O’Dowd, C. D., Facchini, M. C., Cavalli, F., Ceburnis, D., Mircea, M., Decesari, S., Fuzzi, S., Yoon, Y. J., and Putaud, J. P.: Biologically-driven organic contribution to marine aerosol, Nature, 431, 676-680, doi:10.1038/nature02959, 2004.

Petters, M. D., Prenni, A. J., Kreidenweis, S. M., and DeMott, P. J.: On measuring the critical diameter of cloud condensation nuclei using mobility selected aerosol, Aerosol Sci. Tech., 41, 907-913, 2007.

Rissman, T. A., Varutbangkul, V., Surratt, J. D., Topping, D. O., McFiggans, G., Flagan, R. C., and Seinfeld, J. H.: Cloud condensation nucleus $(\mathrm{CCN})$ behavior of organic aerosol particles generated by atomization of water and methanol solutions, Atmos. Chem. Phys., 7, 2949-2971, doi:10.5194/acp-7-2949-2007, 2007.

Roberts, G. C. and Nenes, A.: A continuous-flow streamwise thermal-gradient $\mathrm{CCN}$ chamber for atmospheric measurements, Aerosol Sci. Technol., 39, 206-221, 2005.

Rose, D., Gunthe, S. S., Mikhailov, E., Frank, G. P., Dusek, U., Andreae, M. O., and Pöschl, U.: Calibration and measurement uncertainties of a continuous-flow cloud condensation nuclei counter (DMT-CCNC): CCN activation of ammonium sulfate and sodium chloride aerosol particles in theory and experiment, Atmos. Chem. Phys., 8, 1153-1179, doi:10.5194/acp-8-11532008, 2008.
Sjogren, S., Gysel, M., Weingartner, E., Baltensperger, U., Cubison, M. J., Coe, H., Zardini, A. A., Marcolli, C., Krieger, U. K., and Peter, T.: Hygroscopic growth and water uptake kinetics of twophase aerosol particles consisting of ammonium sulfate, adipic and humic acid mixtures, J. Aerosol Sci., 38, 157-171, 2007.

Swietlicki, E., Zhou, J., Covert, D. S., Hämeri, K., Busch, B., Väkeva, M., Dusek, U., Berg, O. H., Wiedensohler, A., Aalto, P., Mäkelä, J., Martinsson, B. G., Papaspiropoulos, G., Mentes, B., Frank, G., and Stratmann, F.: Hygroscopic properties of aerosol particles in the north-eastern Atlantic during ACE2, Tellus B, 52, 201-227, 2000.

Swietlicki, E., Hansson, H. C., Hameri, K., Svenningsson, B., Massling, A., McFiggans, G., McMurry, P. H., Petaja, T., Tunved, P., Gysel, M., Topping, D., Weingartner, E., Baltensperger, U., Rissler, J., Wiedensohler, A., and Kulmala, M.: Hygroscopic properties of submicrometer atmospheric aerosol particles measured with H-TDMA instruments in various environments - a review, Tellus B, 60, 432-469, 2008.

Topping, D. O., McFiggans, G. B., and Coe, H.: A curved multicomponent aerosol hygroscopicity model framework: Part 1 - Inorganic compounds, Atmos. Chem. Phys., 5, 1205-1222, doi:10.5194/acp-5-1205-2005, 2005.

Topping, D. O., McFiggans, G. B., and Coe, H.: A curved multicomponent aerosol hygroscopicity model framework: Part 2 Including organic compounds, Atmos. Chem. Phys., 5, 1223 1242, doi:10.5194/acp-5-1223-2005, 2005.

Vana, M., Tamm, E., Horrak, U., Mirme, A., Tammet, H., Laakso, L., Aalto, P. P., and Kulmala, M.: Charging state of atmospheric nanoparticles during the nucleation burst events, Atmos. Res., 82, 536-546, 2006.

Wiedensohler, A.: An Approximation of the Bipolar ChargeDistribution for Particles in the Sub-Micron Size Range, J. Aerosol Sci., 19, 387-389, doi:10.1016/0021-8502(88)90278-9, 1988.

Williams, P. I., McFiggans, G., and Gallagher, M. W.: Latitudinal aerosol size distribution variation in the Eastern Atlantic Ocean measured aboard the FS-Polarstern, Atmos. Chem. Phys., 7, 2563-2573, doi:10.5194/acp-7-2563-2007, 2007. 